\title{
The critical view of safety during laparoscopic cholecystectomy: Strasberg Yes or No? An Italian Multicentre study
}

\author{
Lucia llaria Sgaramella ${ }^{1}$. Angela Gurrado ${ }^{1}$ - Alessandro Pasculli ${ }^{1}$. Nicola de Angelis ${ }^{2}$. \\ Riccardo Memeo $^{3}$. Francesco Paolo Prete ${ }^{1}$. Stefano Berti ${ }^{4} \cdot$ Graziano Ceccarelli $^{5} \cdot$ Marco Rigamonti $^{6}$. \\ Francesco Giuseppe Aldo Badessi $i^{7} \cdot$ Nicola Solari $^{8} \cdot$ Marco Milone $^{9} \cdot$ Fausto Catena $^{10}$. Stefano Scabini ${ }^{8}$. \\ Francesco Vittore ${ }^{1}$. Gennaro Perrone ${ }^{10}$. Carlo de Werra ${ }^{9} \cdot$ Ferdinando Cafiero $^{8}$. Mario Testini ${ }^{1} \cdot$ SYoN Italian $^{2}$ \\ Collaborative Group
}

Received: 27 February 2020 / Accepted: 24 July 2020 / Published online: 11 August 2020

(c) The Author(s) 2020

\begin{abstract}
Background Laparoscopic cholecystectomy is considered the gold standard for the treatment of gallbladder lithiasis; nevertheless, the incidence of bile duct injuries (BDI) is still high (0.3-0.8\%) compared to open cholecystectomy $(0.2 \%)$. In 1995, Strasberg introduced the "Critical View of Safety" (CVS) to reduce the risk of BDI. Despite its widespread use, the scientific evidence supporting this technique to prevent BDI is controversial.

Methods Between March 2017 and March 2019, the data of patients submitted to laparoscopic cholecystectomy in 30 Italian surgical departments were collected on a national database. A survey was submitted to all members of Italian Digestive Pathology Society to obtain data on the preoperative workup, the surgical and postoperative management of patients and to judge, at the end of the procedure, if the isolation of the elements was performed according to the CVS. In the case of a declared critical view, iconographic documentation was obtained, finally reviewed by an external auditor.

Results Data from 604 patients were analysed. The study population was divided into two groups according to the evidence (Group A; $n=11$ ) or absence (Group B; $N=593$ ) of BDI and perioperative bleeding.

The non-use of CVS was found in 54.6\% of procedures in the Group A, and $25.8 \%$ in the Group B, and evaluating the operator-related variables the execution of CVS was associated with a significantly lower incidence of BDI and intraoperative bleeding.

Conclusions The CVS confirmed to be the safest technique to recognize the elements of the Calot triangle and, if correctly performed, it significantly impacted on preventing intraoperative complications. Additional educational programs on the correct application of CVS in clinical practice would be desirable to avoid extreme conditions that may require additional procedures.
\end{abstract}

Keywords Cholecystectomy $\cdot$ Critical view of safety $\cdot$ Laparoscopy $\cdot$ Bile duct injuries $\cdot$ Intraoperative bleeding . Laparoscopic training

Laparoscopic cholecystectomy (LC) is currently and worldwide considered the gold standard for the treatment of gallbladder lithiasis. Since its introduction, in the early 1990s,

Accepted as oral presentation at the ESS XXIV annual meeting, May 28-30 2020, Genoa.

Lucia Ilaria Sgaramella

ilaria.sgaram@gmail.com

Extended author information available on the last page of the article this procedure has gained a remarkable consensus until becoming a routine surgical procedure.

$\mathrm{LC}$ is characterized by a reduction in postoperative pain, hospital stay, and recovery times to normal daily activities, which translates into reduced costs for the national healthcare systems (NHS) [1]. However, this procedure comes with an increased incidence of bile duct injuries (BDI), compared to open cholecystectomy (OC): $0.3 \%$ and $0.8 \%$ vs $0.2 \%$ [2-7].

LC-related BDIs include minor injuries up to complex hilar injuries, as classified by Strasberg et al., in which the 
most severe types correspond to type $\mathrm{E}$ injuries including ongoing stricture, complete occlusion, resection or division of the bile ducts $[8,9]$. The management of BDI may require additional treatments ranging from endoscopic retrograde cholangiopancreatography (ERCP) to restorative surgery, up to hepatic transplantation in selected cases, leading to a significant increase in postoperative morbidity, mortality, and costs. Risk factors of BDI can be divided in patient- and surgery-related $[10,11]$.

Although the focus in the current literature has been on biliary complications of LC, the risk of intraoperative bleeding has also been reported with a variable incidence in many series and case reports $[12,13]$.

Intra- or postoperative bleeding in case of LC represents an important, but poorly documented, complication ranging from minor haematomas to significant bleeds (missed operative injuries, slippage of clips) potentially requiring blood transfusion or re-intervention. It has been reported as the most frequent cause of procedure-related mortality in LC (after anaesthesia-related deaths) [13, 14].

The cornerstones for performing a safe cholecystectomy include an adequate knowledge of normal anatomy and related variants, an identification of predictive factors for difficult surgery, and the employment of a correct technique. Since the introduction of laparoscopy, the "infundibular" technique (IT) and the intraoperative recognition of cystic duct and gallbladder junction for gallbladder hilar dissection have been primarily used. In alternative to IT, Strasberg introduced in 1995 the "Critical View of Safety" (CVS) to promote the recognition of the gallbladder elements to reduce the risk of BDI and to avoid mistakes due to anatomical alterations and altered visual perception [8]. The importance of the CVS was also recently recognized by the Society of American Gastrointestinal and Endoscopic Surgeons (SAGES), who encouraged the use of this technique in the "Safe Cholecystectomy Program" to minimize BDI risk and promoted the adoption of a universal culture of safety in cholecystectomy (https: // www.sages.org/safe-cholecyste ctomy-program/). However, despite the widespread use of CVS, a significant BDI decrease has not yet been recorded. Moreover, the scientific evidence supporting this technique to prevent BDI is controversial [15-18]. Several studies, indeed, suggest that the regular use of CVS can reduce or eliminate the risk of BDI; nevertheless, the impossibility to consider a control group burdens the same studies [10, 19]. Meanwhile, other studies contrast the widespread consensus for the technique in the scientific community, showing that CVS is not associated with a useful and correct application in clinical practice [10, 19-23].

This prospective study aimed to assess the impact of the correct application of CVS principles during LC on the incidence of postoperative complications, such as BDI and bleeding.

\section{Materials and methods}

The SYoN (Strasberg Yes or No) study is a multicentre Italian observational prospective cohort study, performed by collecting and analysing clinical data of patients managed in 30 Italian surgical departments affiliated with the Italian Digestive Pathology Society (SIPAD), over a study period of 2 years.

All members of SIPAD have been invited by email to participate in the study through an online questionnaire. The questionnaire (23 questions divided into six forms) examined the preoperative workup, the laparoscopic training of the first surgeon, the intraoperative management of the patient, and the postoperative phase concerning any $\mathrm{BDI}$ and perioperative bleeding.

All involved centres had a critical volume $>100$ laparoscopic cholecystectomies performed per year.

The study was conducted prospectively. The insertion of patients' data in the national database was performed after patient discharge. Patients, indeed, received the most suitable surgical treatment based on their clinical conditions, the preoperative study and the intraoperative findings.

To ensure standardization among the enrolled centres, these were provided with definitions of pathological obesity (BMI $\geq 30 \mathrm{~kg} / \mathrm{m}^{2}$ ), biliary leakage (presence of bile in abdominal drains lesser than 300-500 per day or intraabdominal collections) [24, 25], bleeding (defined as loss of blood ranging from minor haematomas to significant bleeds that require re-operation or blood transfusions) [13], iatrogenic lesions according to Strasberg classification and CVS.

The CVS was achieved when these three fundamental components were respected: (1) the Calot triangle (bordered by the cystic duct, common hepatic duct, and inferior liver edge) is liberated from the surrounding fibrous and fat tissue, (2) the lower third of the gallbladder is separated from the liver up to the visualization of the surface of the liver with evidence of the Rouviere sulcus through the dissected area, (3) the sure recognition of two unique structures that enter into gallbladder.

The surgeon was asked to judge personally, at the end of the procedure, if the isolation of the elements was performed according to all the points described by Strasberg; subsequently, during questionnaire filling, the surgeon introduced, at the same time, data on pre-, intra- and postoperative patient course attaching an iconographic item (Video or "Doublet Photography") in case of confirmed dissection of the Calot triangle with a correct CVS application.

Patients submitted to emergency or elective LC, for acute cholecystitis (AC), chronic pathologies, and during other major laparoscopic surgeries were eligible for 
inclusion, if a proper preoperative examination was conducted by the operating surgeon. Patients who needed conversion to open surgery or who underwent surgery with evidence of malignant pathologies of the gallbladder were excluded.

During compilation, the iconographic documentation (video or photo) was sent to a dedicated encrypted email address indicating the date of the surgery, the patient's initials, the date of birth and the recruiting centre. Data collection was centrally recorded into an electronic database of the data manager (SIPAD), which also ensured the blinding of the lead operator. Finally, an expert surgeon with high skill in hepatobiliary and laparoscopic surgery reviewed, as external auditor, all the iconographic documentation to establish the strict adherence of the declared manoeuvre with the three principles of the CVS of Strasberg. Figure 1 reports some intraoperative photo of the Calot triangle dissection according to CVS principles and reviewed by the external auditor.

The Ethics Committee of the University of Bari (Italy) approved the study (protocol n. 5674, 08/06/2018). Since no different interventions were performed, and patients were treated after signing a written consent form for the recording and research use of iconographic documentation, the Ethics Committee exempted it from the Research Involving Human Subjects Act.

The participating centres contributed by enrolling different numbers of patients, also starting the recruitment at different times. The enrolment was stopped once we reached a sufficient sample of patients for statistical analysis. To integrate the data obtained, at the end of the enrolment, all the centres were interrogated on the conversion rate recorded in each unit during the study period.

This study could not be randomized for ethical reasons and was blinded for the operators who analysed the iconographic findings and for the statistician.

\section{Statistics}

The statistical analysis was carried out with STATA14 (StataCorp LLC, College Station, TX, USA). A $p$ value $<0.05$ was considered statistically significant. The univariate analysis was performed with the $\chi^{2}$ and Fisher's
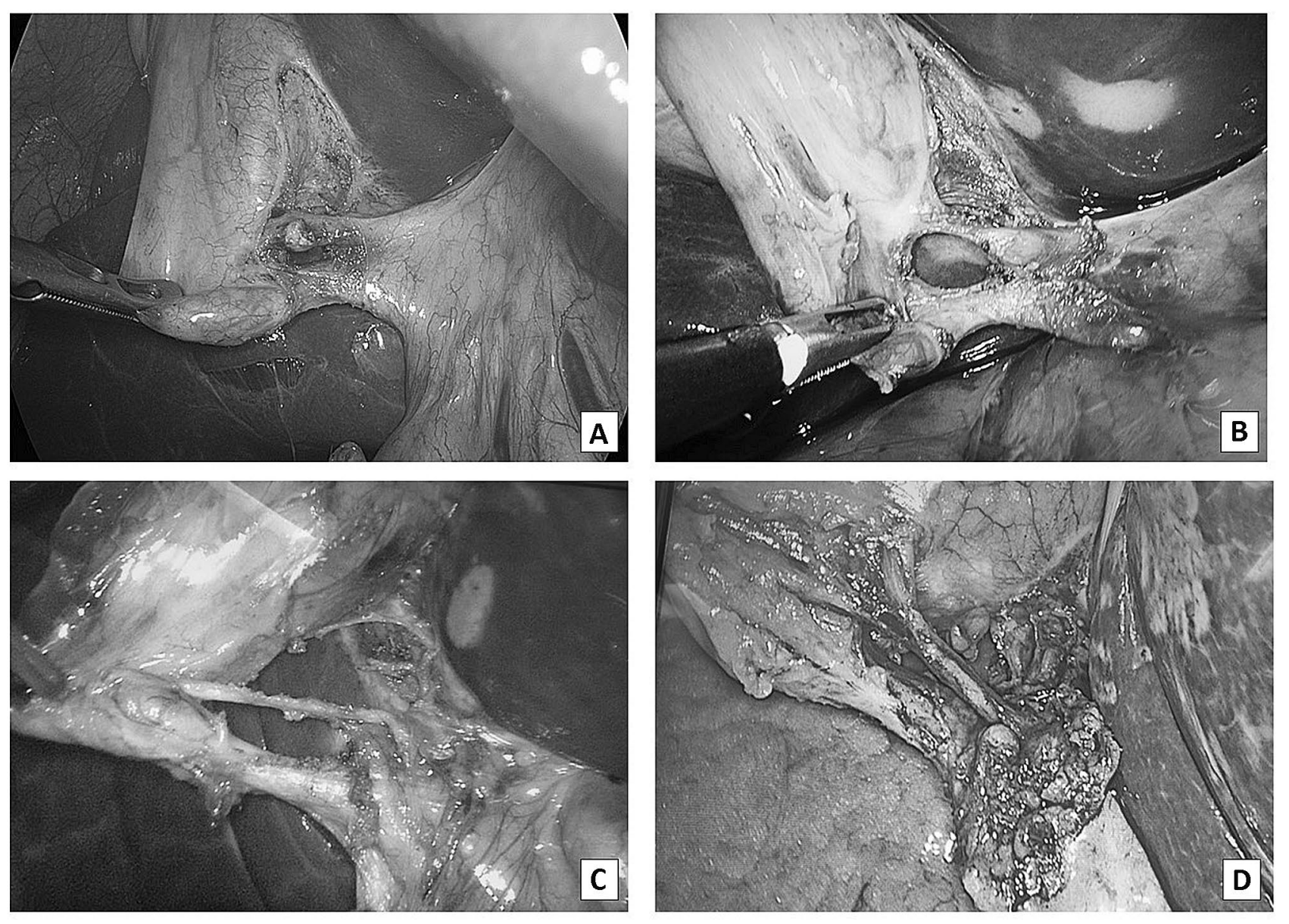

Fig. 1 A-D Intraoperative photo of the Calot's triangle dissection according to CVS principles and reviewed by the external auditor 
exact test, when appropriate. In the analysis, we included covariates known to influence BDI occurrence based on the current literature [17, 26-30]. For instance, we analysed the incidence of sex on BDI based on the experience of Fullum et al. who reported that men have a higher incidence of BDI after cholecystectomy compared to women [26]; we considered both the abdominal circumference and pathological obesity (BMI $>30 \mathrm{~kg} / \mathrm{m}^{2}$ ), as the literature showed that obese patients are 3 times more likely to have a CBD injury as compared to their counterparts [27]. We explored, also, the impact of previous abdominal surgery on BDI based on the historical evidence that prior upper abdominal surgery could be considered as a risk factor for difficult laparoscopic cholecystectomy due to presence of adhesions [28], and the median operative duration as possible expression of surgical difficulty in case of operative durations $>60 \mathrm{~min}$ [29]. Finally, according to Tokyo guidelines for acute cholecystitis and WSES guidelines, we discussed the role of acute cholecystitis in influencing BDI incidence $[17,30]$. The multivariate analysis was carried out with a logistic regression model, reporting Odds Ratios (OR) and 95\% confidence intervals (95\% CI) to estimate the effect of the Critical View of Safety on BDI and bleeding by adjusting for the significant variables identified by the univariate analysis.

\section{Results}

Between March 2017 and March 2019, data of 712 patients submitted to LC were collected in the national database. Out of these, 604 were analysed, 330 females (54.6\%) and 274 males (45.4\%), while 108 (15.2\%) were excluded: 9 because of a missed correspondence with the surgeon's declaration on the CVS employment and the external auditor's opinion, 64 for uncomplete data and 35 for conversion in open surgery.

\section{Patient-related risk factors}

In the $81.9 \%(n=495)$ of patients, the indication for surgery was gallbladder lithiasis; in $18.1 \%(n=109)$ surgery was performed for AC. In $8.1 \%(n=49)$ surgery was performed within $24 \mathrm{~h}$, and in $91.9 \%(n=555)$ patients were managed with deferred urgency. At the time of surgery, 163 patients $(27.0 \%)$ had notable abdominal adiposity with an abdominal circumference $>88 \mathrm{~cm}$ in women and $>102 \mathrm{~cm}$ in men, whereas 58 patients reported preoperative pathological obesity $(9.6 \%)$. Previous upper abdominal surgery was reported in $2.8 \%$ patients $(n=17)$, lower abdominal in $29.3 \%(n=177)$, and both in only $0.2 \%(n=1)$. Among the preoperative parameters evaluated, $8.3 \%(n=50)$ of patients had significant comorbidities on admission.

\section{Surgery-related risk factors}

The laparoscopic surgical training obtain relevance in the data investigation and the results highlight that in $4.6 \%$ $(n=28)$ of cases surgery was performed by young surgeons with a laparoscopic training of less than $30 \mathrm{LC}$; in $5.8 \%$ $(n=35)$ by surgeons who performed 30 to $50 \mathrm{LC}$, whereas the great majority of procedures $(89.6 \%)$ were carried out by experienced surgeons with a training of more than 50 LC. In $51.5 \%$ of cases, the duration of surgery exceeded $60 \mathrm{~min}$ (range: 25- $240 \mathrm{~min}$ ). The external auditor reviewed the entire iconographic documentation. The correct application of CVS was observed in $73.7 \%(n=445)$ of LC, whereas the non-use of CVS was found in $26.3 \%(n=159)$.

\section{Predictors of complications: BDI and/or bleeding}

The study population was then divided into two groups based on the evidence (Group A; $n=11,1.8 \%$ ) or absence (Group B; $n=593,98.2 \%$ ) of BDI and perioperative bleeding after LC.

Table 1 Characteristics of BDI group

\begin{tabular}{llll}
\hline $\begin{array}{l}\text { BDI (Strasberg clas- } \\
\text { sification) }\end{array}$ & $\begin{array}{l}\text { BDI Group } \\
(n=5)\end{array}$ & CVS & No-CVS \\
\hline Type A & 3 & $\begin{array}{c}\text { 1 lesion conservatively managed by } \\
\text { ERCP, and sphincterotomy }\end{array}$ & 2 lesions conservatively managed by ERCP, and sphincterotomy \\
Type B & $/$ & $/$ & $/$ \\
Type C & $/$ & $/$ & $/$ \\
Type D & $/$ & $/$ & $\begin{array}{l}\text { 2 lesions located }>2 \text { cm from the upper biliary confluent: } \\
\text { End-to-end biliary anastomosis of the common bile duct } \\
\text { Type E }\end{array}$ \\
& 2 & & $\begin{array}{c}\text { Hepaticojejunostomy with a trans-anastomotic stent }+ \text { acciden- } \\
\text { tal interruption of right hepatic artery }\end{array}$ \\
\hline
\end{tabular}


Table 1 summarizes demographic data, preoperative findings, patient-related risk factors, surgery-related risk factors, treatment, and postoperative management of both groups.

The non-use of CVS was found in $54.6 \%$ of procedures in the Group A, and 25.8\% in the Group B.

Considering a subgroup consisting of patients with evidence of BDI alone (BDI group; $n=5)$, one patient (20\%) developed BDI in conditions of declared CVS, whereas in the remaining 4 patients (80\%), CVS was not applied. Patient who reported a BDI in case of CVS presented a lesion type A managed by ERCP, and sphincterotomy. The subgroup of BDI without the employment of CVS was comprehensive of two complete lesions of the major bile ducts located $>2 \mathrm{~cm}$ from the upper biliary confluent (type E), one of which is associated with vascular injury, and two leaks from cystic or accessory ducts (type A) treated with ERCP, and sphincterotomy. Both cases of type $\mathrm{E}$ lesions were managed with re-surgery and with an early end-to-end biliary anastomosis of the common bile duct with a trans-anastomotic stent and a hepaticojejunostomy, respectively. This last case reported the association of BDI and vascular injury (accidental interruption of right hepatic artery) supplied by the portal vein and collateral arterial channel pathways (Table 1), as demonstrated by CT scan and liver function blood test.

Among the cohort of 604 patients analysed, 8 (1.3\%) cases presented bleeding that was conservatively managed.

No patients with surgical emergency management for $\mathrm{AC}$ (109 patients) have developed intra- or postoperative complications. Among these, in majority of cases $(67.9 \% ; n=74)$ a correct CVS application was reported and no patients have been treated by surgeon with less than 30 cholecystectomy performed.

During the enrolment period, all involved centres registered a conversion rate ranging from 3 to $9 \%$ (average: $4.9 \%$ ), and the most common reasons were the need for CBD exploration due to the altered Calot's triangle anatomy, BDI, and/or intraoperative bleeding. Conversion to open surgery were caused by BDI in 5 patients (14.3\% of converted cases) and bleeding in one case (2.8\%).

No patient died during the study period.

\section{Univariate and multivariate analysis}

By evaluating in univariate analysis (Table 2), the patientrelated preoperative variables, the abdominal circumference

Table 2 Univariate analysis

\begin{tabular}{|c|c|c|c|c|c|c|}
\hline & & & Tot $(N=604)$ & $\begin{array}{l}\text { Group A: BDI and/or } \\
\text { perioperative bleeding } \\
(N=11)\end{array}$ & $\begin{array}{l}\text { Group B: absence } \\
\text { of complications } \\
(N=593)\end{array}$ & $\mathrm{P}^{\mathrm{a}}$ \\
\hline \multirow{12}{*}{$\begin{array}{l}\text { Patient- } \\
\text { related } \\
\text { risk } \\
\text { factors } \\
(\%)\end{array}$} & \multirow[t]{2}{*}{ Sex } & M & $274(45.4)$ & $8(72.7)$ & $266(44.9)$ & \multirow[t]{2}{*}{0.066} \\
\hline & & $\mathrm{F}$ & $330(54.6)$ & $3(27.3)$ & $327(55.1)$ & \\
\hline & Acute cholecystitis & & $109(18.1)$ & $0(0)$ & $109(18.4)$ & 0.228 \\
\hline & Weight $>75 \mathrm{~kg}$ & & $273(45.2)$ & $4(36.4)$ & $269(45.4)$ & 0.552 \\
\hline & $\begin{array}{l}\text { Abdominal circumference } \\
\qquad(>88 \mathrm{~cm} F,>102 \mathrm{~cm} \mathrm{M})\end{array}$ & & $163(27.0)$ & $0(0)$ & $163(27.5)$ & 0.042 \\
\hline & \multirow[t]{2}{*}{ Setting of surgery } & Emergency & $49(8.1)$ & $0(0)$ & $49(8.3)$ & \multirow[t]{2}{*}{1.000} \\
\hline & & Election & 555 (91.9) & $11(100)$ & 544 (91.7) & \\
\hline & \multirow[t]{3}{*}{ Previous surgery } & Upper abdominal surgery & $17(2.8)$ & $0(0)$ & $17(2.9)$ & \multirow[t]{3}{*}{0.419} \\
\hline & & Lower abdominal surgery & $177(29.3)$ & $1(9.1)$ & $176(29.7)$ & \\
\hline & & $\begin{array}{l}\text { Upper and Lower abdomi- } \\
\text { nal surgery }\end{array}$ & $1(0.2)$ & $0(0)$ & $1(0.2)$ & \\
\hline & Pathological obesity & & $58(9.6)$ & $0(0)$ & $58(9.8)$ & 0.612 \\
\hline & Comorbidities & & $50(8.3)$ & $3(27.3)$ & $47(7.9)$ & $\mathbf{0 . 0 5 0}$ \\
\hline \multirow{6}{*}{$\begin{array}{l}\text { Surgeon- } \\
\text { related } \\
\text { risk } \\
\text { factors } \\
(\%)\end{array}$} & \multirow[t]{3}{*}{ Surgeon's training } & $<30$ & $28(4.6)$ & $0(0)$ & $28(4.7)$ & \multirow[t]{3}{*}{0.705} \\
\hline & & $>30<50$ & $35(5.8)$ & $1(9.1)$ & $34(5.7)$ & \\
\hline & & $>50$ & $541(89.6)$ & $10(90.9)$ & $531(89.5)$ & \\
\hline & $\begin{array}{l}\text { Duration of sur- } \\
\text { gery }>60 \text { min }\end{array}$ & & $311(51.5)$ & $8(72.7)$ & $303(51.1)$ & 0.155 \\
\hline & \multirow[t]{2}{*}{ Strasberg's CVS } & Performed & 445 (73.7) & $5(45.4)$ & $440(74.2)$ & \multirow[t]{2}{*}{0.032} \\
\hline & & Not performed & $159(26.3)$ & $6(54.6)$ & $153(25.8)$ & \\
\hline
\end{tabular}

Data are given as absolute values and percentages. Group A: BDI and/or perioperative bleeding; Group B: absence of complications

${ }^{a}$ Between-group comparison made using $\chi^{2}$ and Fisher's exact test. Bold emphasized values are statistically significant. $P<0.05$ was considered statistically significant 
( $>88 \mathrm{~cm}$ in females and $>102 \mathrm{~cm}$ in males) emerged, unexpectedly, as a protective prognostic factor for BDI or bleeding $(p=0.04)$. The preoperative diagnosis of $\mathrm{AC}(p=0.22)$, the setting of surgery (election or emergency; $p=1.0$ ), the history of previous operations $(p=0.41)$ and the pathological obesity $(p=0.61)$ in the analysed sample were not associated with the unfavourable progress of the surgical intervention. On the contrary, the presence of comorbidities (more than 1 comorbidity) appeared to detect a frail sample of population with a worse prognosis and was significantly associated $(p=0.05)$ with intraoperative complications. Concerning the operator-related variables, the laparoscopic training $(p=0.70)$ was not associated with the development of intraoperative complications, whereas the execution of CVS was associated with a significantly lower incidence of BDI and intraoperative bleeding ( $p=0.03$ ). The multivariate analysis (Table 3) showed that the presence of preoperative comorbidity is a risk factor for BDI and intraoperative bleeding $(p=0.003)$, whereas the employment of CVS played a protective role in preventing intraoperative complications $(p=0.04)$. Together with this, the preoperative comorbidity maintained statistical significance $(p=0.003)$ while the presence of high abdominal circumference lost significance. Finally, considering the univariate analysis on group with perioperative complications, because of the smallness of the sample under examination, the same parameters lost significance.

\section{Discussion}

Numerous studies have questioned the incidence of BDI during LC by analysing its causes and risk factors and demonstrating how the incidence rate during $\mathrm{LC}$ is still double compared to the OC.

In 1992, Morgenstern et al. reported on 1200 consecutive open cholecystectomies a BDI incidence rate $<0.2 \%$ and at the same time considered this value the standard on which LC should be compared [31]. In 2003, Flum et al., analysing a North American database of 1,570,361 cholecystectomies, showed that the incidence of BDI was

Table 3 Multivariate analysis

\begin{tabular}{lll}
\hline & OR $(95 \% \mathrm{CI})$ & $p^{\mathrm{a}}$ \\
\hline Abdominal circumference & na & na \\
Comorbidities & $9.02(2.13-38.28)$ & 0.003 \\
Strasberg' CVS & $0.28(0.08-0.98)$ & 0.046 \\
\hline
\end{tabular}

OR $(95 \% \mathrm{CI})$ : odds ratio $(95 \%) \cdot p(<0.05)$

${ }^{a}$ Between-group comparison made using multivariate logistic regression, adjusting ORs for abdominal circumference, comorbidities and Strasberg
$0.5 \%$ and, as confirmed by Way et al., it rose in cases of $\mathrm{AC}$, especially in case of conversions to open surgery with an overall rate of $1.2 \%[11,32,33]$. During the first 5 years of LC introduction, the procedure was associated with the occurrence of serious complications, some of which are typical of laparoscopic access and not common to open surgery. At the beginning, indeed, the incidence of duodenal and bowel injuries, due to trocar puncture or coagulation necrosis of the bowel wall resulting in delayed or walled-off perforation, were reported with an incidence rate of $0.07-0.9 \%$ ( $0.04 \%$ for duodenal injury). Major vessel and bile duct injury were described with incidence rates up to $4 \%[8,11,34]$. Nowadays, this rate is hopefully much lower and ranges between 0.3 and $0.8 \%$, but remains two to three times higher than the injury rates reported for OC [2].

The higher incidence of BDI in LC questioned the appropriate preoperative evaluation of complex cases, the training of surgeons ready to face them and the common risk factors. According to the current literature, the numerous anatomical variants of the biliary tract represent a possible explication of iatrogenic injury but, also pathological obesity, previous surgery on the biliary tract, and an underlying liver disease, may be seen as predisposing factors for perioperative complications [35, 36]. Aziz et al., indeed, on a national database analysis, report that obese patients are three times more likely to have a BDI as compared to their counterparts [27]. Moreover, Kholdebarin et al. [28] report that previous abdominal surgery, especially the upper one, has historically been considered by some authors $[37,38]$ but not others $[39,40]$ to be a relative contraindication to laparoscopic cholecystectomy and usually associated with a high risk of BDI due to the presence of adhesions. In this reported study, both pathological obesity and previous abdominal surgery were not associated with an unfavourable surgery. It could be likely interpreted as a random factor, or related to the higher alert required for potentially more technically demanding surgery. Moreover, the significative correlation between different comorbidities and BDI do not find an exhaustive validation in the current literature and should be interpreted as expression of a frail sample of population with a major risk of an adverse surgical outcome [41].

In case of AC, BDI takes place three times more often in patients with severe local conditions due to active $\mathrm{AC}$ if compared with patients without inflammation. Indeed, the literature reports that the risk of BDI depends on the severity of the inflammation and the patient's preoperative clinical condition [42-44]. The data analysed in this study, in which no BDI occurred in patients who underwent emergency surgery, are in disagreement with these previously reported data but could be evaluated in consideration of experienced surgeons involvement in the management of potentially difficult cholecystectomies. Contrariwise, these results find 
validation and confirm in a Cochrane review and other recent observational studies. These studies highlighted, indeed, that early LC (within $48 \mathrm{~h}$ ) during $\mathrm{AC}$ is related to lower surgical complications and lower incidence of BDI, also reducing operative time in comparison to an antibiotic-first approach followed by elective or deferred surgery $[45,46]$.

In the most recent Tokyo guidelines for AC, the CVS proposed by Strasberg is strongly recommended to prevent BDI. Nevertheless, in case of severe inflammation with subversion of the Calot triangle anatomy, the application of CVS could be arduous, leading to consider alternative procedures, such as fundus-first cholecystectomy, subtotal one, or conversion to open surgery [17]. Also, in WSES guidelines for AC, subtotal cholecystectomy and alternative surgical strategy are considered as an important tool in the difficult cholecystectomy [30,47], useful in case of severe anatomical alteration of Calot triangle when surgical dissection and performability of Strasberg manoeuvre is extremely difficult or hazardous (i.e. Mirizzi syndrome) [48, 49].

Some scoring tools based on intraoperative findings to identify difficult LC have been suggested, and are increasingly recognized [50]. Indeed, Sugrue et al. outlines a surgical scoring system incorporating key operative findings to allow grading and standardization of the degree of cholecystitis [51]. Afterwards, Iwashita et al., in the Japan-KoreaTaiwan expert Delphi consensus on surgical difficulty during laparoscopic cholecystectomy, established that the evaluation of the inflammatory tissue surrounding the gallbladder, the state of the Calot triangle and the gallbladder bed could offer an objective parameter, and that the use of this scale may be desirable in future studies [52].

When the CVS cannot be safely obtained during dissection of Calot's triangle, conversion to open surgery is advocated to prevent bile duct injury [53]. However, there is a wide variation in the current literature of the conversion rate to open surgery and, in accordance with this reported experience, it ranges from 2 to 15\% [54-56]. According to Al Masri et al. [54], surgery-related indications for conversion includes extensive adhesions, significant inflammation, intraoperative difficulty of bile ducts exploration, and obfuscating bleeding. Medical comorbidities (such as pulmonary disease) have been furthermore found to be a risk factor for conversion from laparoscopic to open surgery in different series and for different laparoscopic procedures [57, 58].

Patients undergoing conversion to open surgery show a higher risk of complications and a longer operative time than those who proceeded successfully with LC [59]. Duration of surgery and conversion rate, indeed, has been cited as generic indicators of surgical difficulty, but should also be interpreted as related factors depending on the surgical training and skill of the operator. As suggested by Bharamgoudar et al., the median operative duration of LC is $60 \mathrm{~min}$ and some factors were found to be significant independent predictors of long operative durations ( $>90 \mathrm{~min}$ ), including ASA, age, previous surgical admissions, BMI, gallbladder wall thickness and common bile duct diameter [29].

Among the surgeon-related risk factors, the role of laparoscopic training is firmly taken into account in the determination of BDI. Some studies report a higher risk of iatrogenic injury among the first cases of LC performed. Moore et al., in a study on 8,839 cholecystectomies performed by 55 different surgeons with different laparoscopic training, showed that $90 \%$ of iatrogenic lesions had occurred within the first 30 cases. Analysis of the data suggests that the risk of injury is $1.7 \%$ for the surgeon in the first case of laparoscopic cholecystectomy and drops to $0.17 \%$ after the 50th case [60]. This evidence is not verifiable in our case studies because of the small sample of cholecystectomies performed by surgeons with a training $<30$ LC. Voitk et al., contrarily to the study mentioned above, suggested that in the learning curve for LC the target to achieve is sufficiently far from the 50 cases, indicating, however, how the surgery time is significantly related with the laparoscopic learning curve and continues to decrease up to 200 cases [61]. Nevertheless a limitation of this study is the absence of correlation between training and iatrogenic lesions. According to other studies, the risk of BDI would not disappear after the first 50 or 200 cases [62]. In a national survey with over 1500 respondents, surgeons reported that about a third of the BDI occurred after 200 cases of LC, demonstrating that injuries could not be related to the surgeon's inexperience but may reflect technical errors [63]. Calvete et al. suggested that no apparent correlation can be found between the surgeon's experience and the incidence of BDI. By analysing 784 patients divided into three groups over a 6-year time period, they showed how the rate of iatrogenic lesions remained similar among the three groups without significant difference [64].

Moreover, LC is primarily based on visual perception, which may be susceptible to errors or misinterpretations. Way et al. analysed 252 BDI, demonstrating that the leading cause of failure, in $97 \%$ of cases, was due to the impaired visual perception rather than poor surgical ability [11].

It appears, indeed, that in most cases the iatrogenic lesion is the result of an intentional surgical manoeuvre that results in an unintentional injury, as a section of the biliary tract, and that in the $75 \%$ of cases, the injury would not be intraoperatively recognized. Similarly, Dekker and Hugh described how the most common cause of BDI is the erroneous interpretation of visual information during surgery with a failure to recognize the cystic duct misinterpreted as biliary tract [65]. In their series of 49 patients with iatrogenic lesions, 42 patients had injuries caused by incorrect identification of anatomical structures, and in $70 \%$ of cases they were not intraoperatively recognized.

The Strasberg's CVS was introduced with the purpose to overcome errors of interpretation of the visual field during 
dissection of the elements of the gallbladder, and this is supported by several studies showing that the routinely use of CVS is associated with a reduction or even elimination of BDI $[66,67]$. The safety of the manoeuvre described by Strasberg is confirmed by the present study in which it is found as a significant protective factor to prevent BDI and/or haemorrhagic complications. Avgerinos et al. analysed 1,046 patients who underwent LC. No BDI occurred in 998 cases when CVS was performed [1]. However, the study did not include a control group, conversely to our reported research. Although the aim of CVS is to reduce BDI during LC, there was no decrease in countries where its use has now become mandatory. Therefore, it has been hypothesized that CVS is useful in preventing major lesions (Type $\mathrm{E}$ ) due to complete erroneous recognition of the anatomy, but fails to avoid injuries type A such as biliary fistulas. This is reflected in this study, in which a complete lesion of the major bile ducts located $>2 \mathrm{~cm}$ from the upper biliary confluent (type E) is reported among the non-Strasberg group [20, 68].

In recent studies, the growing consensus obtained for CVS in the scientific community has clashed with the evidence that this is not associated with a correct application in clinical practice.

Experienced surgeons with adequate laparoscopic training would often claim to have reached CVS, while intraoperative images would demonstrate the opposite and other studies showed that many respondents, senior surgeons too, were not able to adequately discern the essential steps of this technique [21-23, $68,69]$. This is demonstrated by Nijssen et al., who reported that in disagreement with what was declared by the operators $(80 \%$ of the surgeons in the analysis stated to carry out the CVS) from the video analysis of the interventions the CVS would be reached only in $10.8 \%$ of cases [70]. The number of studies reporting this evidence suggests two possibilities: the iconographic documentation does not correspond to the real intraoperative perception or surgeons who supposed to know CVS in truth fails understanding its application. This would reinforce the concept that programmes and task forces for a safe cholecystectomy help to increase the number of surgeons able to act safely and that the use of additional techniques, such as comparison with iconographic findings, can help the operator to have perception of his work and document what has been done [16, 68, 71-73].

This series appears representative for what concerns the overall complication rate, but not for the analysis of separate outcomes. This limitation could be overcome by enlarging the patient sample, allowing the analysis of the CVS influence on bleeding and BDI separately, and the correlation among AC, CVS employment, and BDI.

\section{Conclusion}

In the present study, some factors that are universally recognized in the current literature as risk factors for bile duct injury, such as acute inflammatory conditions and pathological obesity, were not associated with an increased incidence of iatrogenic lesions if managed with appropriate timing and with the correct surgical approach.

The Critical View of Safety, when correctly applied, is confirmed to be the safest technique for recognizing the elements of the Calot triangle, and it is associated with a significant impact in preventing intraoperative complications (iatrogenic lesions and perioperative bleeding). Additional training for the correct application of Critical View of Safety in clinical practice should be desirable to standardize the laparoscopic approach to the gallstone disease.

Acknowledgements Open access funding provided by Università degli Studi di Bari Aldo Moro within the CRUI-CARE Agreement. A special note of thanks to Francesco Corcione for the revision of all the iconographic documentation as external auditor and to Claudia Ventrelli Technical Translator for assistance in the preparation of the English manuscript.

Syon Group: Gian Luca Baiocchi, Gianandrea Baldazzi, Mario Battocletti, Sergio Bertoglio, Paolo Bianco, Walter Bugiantella, Giovanni Ciaccio, Lorenzo Cobianchi, Giovanni Conzo, Michele Crespi, Michele De Rosa, Giovanna Di Meo, Ludovico Docimo, Luca Fabris, Cosimo Feleppa, Valentina Ferraro, Tommaso Fontana, Claudio Gambardella, Andrea Gennai, Francesco Guida, Laura Invernizzi, Andrea Massobrio, Fabio Medas, Luigi Monaco, Gianfranco Muntoni, Mario Musella, Denise Palombo, Roberto Perinotti, Davide Pertile, Angela Pezzolla, Gianluca Piccirillo, Roberto Polastri, Roberto Ruggiero, Marco Scatizzi, Carlo Somaglino, Salvatore Tolone, Enrico Traverso, Roberta Tutino, Carlo Valduga, Michele Zuolo.

\section{Compliance with ethical standards}

Disclosure Sgaramella Lucia Ilaria, Gurrado Angela, Pasculli Alessandro, de Angelis Nicola, Memeo Riccardo, Prete Francesco Paolo, Berti Stefano, Ceccarelli Graziano, Rigamonti Marco, Badessi Francesco, Solari Nicola, Milone Marco, Catena Fausto, Scabini Stefano, Vittore Francesco, Gennaro Perrone, de Werra Carlo, Cafiero Fernando, Testini Mario and all authors of SYoN collaborative group have no conflicts of interest nor financial ties to disclose.

Open Access This article is licensed under a Creative Commons Attribution 4.0 International License, which permits use, sharing, adaptation, distribution and reproduction in any medium or format, as long as you give appropriate credit to the original author(s) and the source, provide a link to the Creative Commons licence, and indicate if changes were made. The images or other third party material in this article are included in the article's Creative Commons licence, unless indicated otherwise in a credit line to the material. If material is not included in the article's Creative Commons licence and your intended use is not permitted by statutory regulation or exceeds the permitted use, you will need to obtain permission directly from the copyright holder. To view a copy of this licence, visit http://creativecommons.org/licenses/by/4.0/. 


\section{References}

1. Avgerinos C, Kelgiorgi D, Touloumis Z, Baltatzi L, Dervenis C (2009) One thousand laparoscopic cholecystectomies in a single surgical unit using the "critical view of safety" technique. J Gastrointest Surg 13(3):498-503

2. Russell JC, Walsh SJ, Mattie AS, Lynch JT (1996) Bile duct injuries 1989-1993. A statewide experience Connecticut Laparoscopic Cholecystectomy Registry. Arch Surg 131(4):382-388

3. Caputo L, Aitken DR, Mackett MC, Robles AE (1992) Iatrogenic bile duct injuries. The real incidence and contributing factors-implications for laparoscopic cholecystectomy. Am Surg 58(12):766-771

4. Fletcher DR, Hobbs MS, Tan P, Valinsky LJ, Hockey RL, Pikora TJ et al (1999) Complications of cholecystectomy: risks of the laparoscopic approach and protective effects of operative cholangiography: a population-based study. Ann Surg 229(4):449-457

5. Tornqvist B, Stromberg C, Persson G, Nilsson M (2012) Effect of intended intraoperative cholangiography and early detection of bile duct injury on survival after cholecystectomy: population based cohort study. BMJ 11(345):e6457

6. Huang X, Feng Y, Huang Z (1997) Complications of laparoscopic cholecystectomy in China: an analysis of 39,238 cases. Chin Med J 110(9):704-706

7. Waage A, Nilsson M (2006) Iatrogenic bile duct injury: a population-based study of 152776 cholecystectomies in the swedish inpatient registry. Arch Surg 141(12):1207-1213

8. Strasberg SM, Hertl M, Soper NJ (1995) An analysis of the problem of biliary injury during laparoscopic cholecystectomy. J Am Coll Surg 180(1):101-125

9. Strasberg SM (2002) Avoidance of biliary injury during laparoscopic cholecystectomy. J Hepatobiliary Pancreat Surg 9(5):543-547

10. McKinley SK, Brunt LM, Schwaitzberg SD (2014) Prevention of bile duct injury: the case for incorporating educational theories of expertise. Surg Endosc 28(12):3385-3391. https://doi. org/10.1007/s00464-014-3605-8

11. Way LW, Stewart L, Gantert W, Liu K, Lee CM, Whang K et al (2003) Causes and prevention of laparoscopic bile duct injuries: analysis of 252 cases from a human factors and cognitive psychology perspective. Ann Surg 237(4):460-469

12. Gupta V, Gupta V, Joshi P, Kumar S, Kulkarni R, Chopra N et al (2019) Management of post cholecystectomy vascular injuries. Surgeon 17(6):326-333. https://doi.org/10.1016/j.surge .2018 .10 .002

13. Kaushik R (2010) Bleeding complications in laparoscopic cholecystectomy: Incidence, mechanisms, prevention and management. J Minim Access Surg 6(3):59-65. https://doi. org/10.4103/0972-9941.68579

14. Phillips PA, Amaral JF (2001) Abdominal access complications in laparoscopic surgery. J Am Coll Surg 192:525-536

15. Pucher PH, Brunt LM, Fanelli RD, Asbun HJ, Aggarwal R (2015) SAGES expert Delphi consensus: critical factors for safe surgical practice in laparoscopic cholecystectomy. Surg Endosc 29:3074-3085

16. Conrad C, Wakabayashi G, Asbun HJ, Dallemagne B, Demartines $\mathrm{N}$, Diana M et al (2017) IRCAD recommendation on safe laparoscopic cholecystectomy. J Hepatobiliary Pancreat Sci 24(11):603615. https://doi.org/10.1002/jhbp.491

17. Wakabayashi G, Iwashita Y, Hibi T, Takada T, Strasberg SM, Asbun HJ et al (2018) Tokyo Guidelines 2018: surgical management of acute cholecystitis: safe steps in laparoscopic cholecystectomy for acute cholecystitis (with videos). J Hepatobiliary Pancreat Sci 25:73-86
18. Strasberg SM, Brunt LM (2017) The critical view of safety: why it is not the only method of ductal identification within the standard of care in laparoscopic cholecystectomy. Ann Surg 265(3):464 465. https://doi.org/10.1097/SLA.0000000000002054

19. Heistermann HP, Tobusch A, Palmes D (2006) Prevention of bile duct injuries after laparoscopic cholecystectomy. "The critical view of safety". Zentralbl Chir 131(6):460-465 German

20. Stefanidis D, Chintalapudi N, Anderson-Montoya B, Oommen B, Tobben D, Pimentel M (2017) How often do surgeons obtain the critical view of safety during laparoscopic cholecystectomy? Surg Endosc 31(1):142-146. https://doi.org/10.1007/s0046 4-016-4943-5

21. Daly SC, Deziel DJ, Li X, Thaqi M, Millikan KW, Myers JA et al (2016) Current practices in biliary surgery: do we practice what we teach? Surg Endosc 30(8):3345-3350

22. Chen CB, Palazzo F, Doane SM, Winter JM, Lavu H, Chojnacki $\mathrm{KA}$ et al (2017) Increasing resident utilization and recognition of the critical view of safety during laparoscopic cholecystectomy: a pilot study from an academic medical center. Surg Endosc 31(4):1627-1635

23. van de Graaf FW, van den Bos J, Stassen LPS, Lange JF (2018) Lacunar implementation of the critical view of safety technique for laparoscopic cholecystectomy: results of a nationwide survey. Surgery. https://doi.org/10.1016/j.surg.2018.01.016

24. Christoforidis E, Goulimaris I, Tsalis K, Kanellos I, Demetriades H, Betsis D (2002) The endoscopic management of persistent bile leakage after laparoscopic cholecystectomy. Surg Endosc 16(5):843-846. https://doi.org/10.1007/s00464-001-9091-9

25. Sultan AM, Elnakeeb AM, Elshobary MM, El-Geidi AA, Salah T, El-Hanafy EA et al (2015) Management of post-cholecystectomy biliary fistula according to type of cholecystectomy. Endosc Int Open 3(1):E91-E98. https://doi.org/10.1055/s-0034-1390747

26. Fullum TM, Downing SR, Ortega G, Chang DC, Oyetunji TA, Van Kirk K et al (2013) Is laparoscopy a risk factor for bile duct injury during cholecystectomy? JSLS 17(3):365-370. https://doi. org/10.4293/108680813X13654754535638

27. Aziz H, Pandit V, Joseph B, Jie T, Ong E (2015) Age and obesity are independent predictors of bile duct injuries in patients undergoing laparoscopic cholecystectomy. World J Surg 39(7):18041808. https://doi.org/10.1007/s00268-015-3010-z. Erratum in: World J Surg 2015 Jul;39(7):1809

28. Kholdebarin R, Boetto J, Harnish JL, Urbach DR (2008) Risk factors for bile duct injury during laparoscopic cholecystectomy: a case-control study. Surg Innov 15(2):114-119. https://doi. org/10.1177/1553350608318144

29. Bharamgoudar R, Sonsale A, Hodson J, Griffiths E, CholeS Study Group, West Midlands Research Collaborative (2018) The development and validation of a scoring tool to predict the operative duration of elective laparoscopic cholecystectomy. Surg Endosc 32(7):3149-3157. https://doi.org/10.1007/s00464-018-6030-6

30. Ansaloni L, Pisano M, Coccolini F, Peitzmann AB, Fingerhut A, Catena $F$ et al (2016) WSES guidelines on acute calculous cholecystitis. World J Emerg Surg 14(11):25. https://doi.org/10.1186/ s13017-016-0082-5. Erratum in: World J Emerg Surg 2016 Nov 4;11:52

31. Morgenstern L, Wong L, Berci G (1992) Twelve hundred open cholecystectomies before the laparoscopic era. A standard for comparison. Arch Surg 127(4):400-403

32. Flum DR, Dellinger EP, Cheadle A, Chan L, Koepsell T (2003) Intraoperative cholangiography and risk of common bile duct injury during cholecystectomy. JAMA 289(13):1639-1644

33. Stewart L, Way LW (1995) Bile duct injuries during laparoscopic cholecystectomy. Factors that influence the results of treatment. Arch Surg 130(10):1123-1128 discussion 1129 
34. Testini M, Piccinni G, Lissidini G, Di Venere B, Gurrado A, Poli E et al (2008) Management of descending duodenal injuries secondary to laparoscopic cholecystectomy. Dig Surg 25(1):12-15. https://doi.org/10.1159/000114196

35. Nuzzo G, Giuliante F, Giovannini I, Ardito F, D’Acapito F, Vellone $\mathrm{M}$ et al (2005) Bile duct injury during laparoscopic cholecystectomy: results of an Italian national survey on 56591 cholecystectomies. Arch Surg 140(10):986-992

36. Tsai CJ, Leitzmann MF, Willett WC, Giovannucci EL (2004) Prospective study of abdominal adiposity and gallstone disease in US men. Am J Clin Nutr 80(1):38-44

37. Schirmer BD, Dix J, Schmieg RE Jr, Aguilar M, Urch S (1995) The impact of previous abdominal surgery on outcome following laparoscopic cholecystectomy. Surg Endosc 9:1085-1089

38. Yu SC, Chen SC, Wang SM, Wei TC (1994) Is previous abdominal surgery a contraindication to laparoscopic cholecystectomy? J Laparoendosc Surg 4:31-35

39. Diez J, Delbene R, Ferreres A (1998) The feasibility of laparoscopic cholecystectomy in patients with previous abdominal surgery. HPB Surg 10:353-356

40. Akyurek N, Salman B, Irkorucu O, Tascilar O, Yuksel O, Sare $M$ et al (2005) Laparoscopic cholecystectomy in patients with previous abdominal surgery. JSLS 9(2):178-183

41. Revenig LM, Canter DJ, Master VA, Maithel SK, Kooby DA, Pattaras JG et al (2014) A prospective study examining the association between preoperative frailty and postoperative complications in patients undergoing minimally invasive surgery. J Endourol 28(4):476-480. https://doi.org/10.1089/end.2013.0496

42. MacFadyen BV Jr, Vecchio R, Ricardo AE, Mathis CR (1998) Bile duct injury after laparoscopic cholecystectomy. The United States experience. Surg Endosc 12(4):315-321

43. Shamiyeh A, Wayant W (2004) Laparoscopic cholecystectomy: early and late complications and their treatment. Langenbecks Arch Surg 389(3):164-171

44. Törnqvist B, Waage A, Zheng Z, Ye W, Nilsson M (2016) Severity of acute cholecystitis and risk of iatrogenic bile duct injury during cholecystectomy, a population-based case-control study. World J Surg 40(5):1060-1067. https://doi.org/10.1007/s0026 8-015-3365-1

45. Gurusamy KS, Davidson C, Gluud C, Davidson BR (2013) Early versus delayed laparoscopic cholecystectomy for people with acute cholecystitis. Cochrane Database Syst Rev 30(6):CD005440. https://doi.org/10.1002/14651858.CD005440.pub3

46. Halpin V, Gupta A (2011) Acute cholecystitis. BMC Clin Evid 20:0411

47. Elshaer M, Gravante G, Thomas K, Sorge R, Al-Hamali S, Ebdewi H (2015) Subtotal cholecystectomy for "difficult gallbladders" systematic review and meta-analysis. JAMA Surg 150(2):159-168

48. Piccinni G, Sciusco A, De Luca GM, Gurrado A, Pasculli A, Testini M (2014) The minimanlly invasive treatment of mirizzi's syndrome: there a safe way? Ann Hepatol 13:558-564

49. Testini M, Sgaramella LI, De Luca GM, Pasculli A, Gurrado A, Biondi A et al (2017) Management of Mirizzi syndrome in emergency. J Laparoendosc Adv Surg Tech A 27(1):28-32. https://doi. org/10.1089/lap.2016.0315

50. Philip Rothman J, Burcharth J, Pommergaard HC, Viereck S, Rosenberg J (2016) Preoperative risk factors for conversion of laparoscopic cholecystectomy to open surgery: a systematic review and meta-analysis of observational studies. Dig Surg 33(5):414-423

51. Sugrue M, Sahebally SM, Ansaloni L, Zielinski MD (2015) Grading operative findings at laparoscopic cholecystectomy: a new scoring system. World J Emerg Surg 8(10):14. https://doi. org/10.1186/s13017-015-0005-x

52. Iwashita Y, Hibi T, Ohyama T, Honda G, Yoshida M, Miura F et al (2017) An opportunity in difficulty: Japan-korea-taiwan expert delphi consensus on surgical difficulty during laparoscopic cholecystectomy. J Hepatobiliary Pancreat Sci 24(4):191-198. https ://doi.org/10.1002/jhbp.440

53. Henneman D, da Costa DW, Vrouenraets BC, van Wagensveld BA, Lagarde SM (2013) Laparoscopic partial cholecystectomy for the difficult gallbladder: a systematic review. Surg Endosc 27(2):351-358. https://doi.org/10.1007/s00464-012-2458-2

54. Al Masri S, Shaib Y, Edelbi M, Tamim H, Jamali F, Batley N et al (2018) Predicting conversion from laparoscopic to open cholecystectomy: a single institution retrospective study. World J Surg 42(8):2373-2382. https://doi.org/10.1007/s00268-018-4513-1

55. Rosen M, Brody F, Ponsky J (2002) Predictive factors for conversion of laparoscopic cholecystectomy. Am J Surg 184(3):254-258. https://doi.org/10.1016/s0002-9610(02)00934-0

56. Zhang WJ, Li JM, Wu GZ, Luo KL, Dong ZT (2008) Risk factors affecting conversion in patients undergoing laparoscopic cholecystectomy. ANZ J Surg 78(11):973-976. https://doi.org/10.111 1/j.1445-2197.2008.04714.x

57. Moghadamyeghaneh Z, Masoomi H, Mills SD, Carmichael JC, Pigazzi A, Nguyen NT et al (2014) Outcomes of conversion of laparoscopic colorectal surgery to open surgery. JSLS 18(4):e2014.00230. https://doi.org/10.4293/JSLS.2014.00230

58. Sippey M, Grzybowski M, Manwaring ML, Kasten KR, Chapman WH, Pofahl WE et al (2015) Acute cholecystitis: risk factors for conversion to an open procedure. J Surg Res 199(2):357-361. https://doi.org/10.1016/j.jss.2015.05.040

59. Lengyel BI, Azagury D, Varban O, Panizales MT, Steinberg J, Brooks DC et al (2012) Laparoscopic cholecystectomy after a quarter century: why do we still convert? Surg Endosc 26(2):508513. https://doi.org/10.1007/s00464-011-1909-5

60. Moore MJ, Bennett CL (1995) The learning curve for laparoscopic cholecystectomy. The Southern Surgeons Club. Am J Surg 170(1):55-59

61. Voitk AJ, Tsao SG, Ignatius S (2001) The tail of the learning curve for laparoscopic cholecystectomy. Am J Surg 182(3):250-253

62. Morgenstern L, McGrath MF, Carroll BJ, Paz-Partlow M, Berci G (1995) Continuing hazards of the learning curve in laparoscopic cholecystectomy. Am Surg 61(10):914-918

63. Archer SB, Brown DW, Smith CD, Branum GD, Hunter JG (2001) Bile duct injury during laparoscopic cholecystectomy: results of a national survey. Ann Surg 234(4):549-558 discussion 558-559

64. Calvete J, Sabater L, Camps B, Verdú A, Gomez-Portilla A, Martín J et al (2000) Bile duct injury during laparoscopic cholecystectomy: myth or reality of the learning curve? Surg Endosc 14(7):608-611

65. Dekker SW, Hugh TB (2008) Laparoscopic bile duct injury: understanding the psychology and heuristics of the error. ANZ J Surg 78(12):1109-1114. https://doi.org/10.111 1/j.1445-2197.2008.04761.x

66. Honda G, Hasegawa H, Umezawa A (2016) Universal safe procedure of laparoscopic cholecystectomy standardized by exposing the inner layer of the subserosal layer (with video). J Hepatobiliary Pancreat Sci 23(9):E14-E19. https://doi.org/10.1002/jhbp.382

67. Barrett M, Asbun HJ, Chien HL, Brunt LM, Telem DA (2018) Bile duct injury and morbidity following cholecystectomy: a need for improvement. Surg Endosc 32(4):1683-1688. https:// doi.org/10.1007/s00464-017-5847-8

68. Sanford DE, Strasberg SM (2014) A simple effective method for generation of a permanent record of the critical view of safety during laparoscopic cholecystectomy by intraoperative " doublet' photography. J Am Coll Surg 218:170-178. https://doi. org/10.1016/j.jamcollsurg.2013.11.003

69. van de Graaf FW, Zaïmi I, Stassen LPS, Lange JF (2018) Safe laparoscopic cholecystectomy: a systematic review of bile duct injury prevention. Int J Surg 60:164-172. https://doi.org/10.1016/j. ijsu.2018.11.006 
70. Nijssen MA, Schreinemakers JM, Meyer Z, van der Schelling GP, Crolla RM, Rijken AM (2015) Complications after laparoscopic cholecystectomy: a video evaluation study of whether the critical view of safety was reached. World J Surg 39(7):1798-1803. https ://doi.org/10.1007/s00268-015-2993-9

71. Mascagni P, Fiorillo C, Urade T, Emre T, Yu T, Wakabayashi T et al (2019) Formalizing video documentation of the Critical View of Safety in laparoscopic cholecystectomy: a step towards artificial intelligence assistance to improve surgical safety. Surg Endosc. https://doi.org/10.1007/s00464-019-07149-3

72. Emous M, Westerterp M, Wind J, Eerenberg JP, van Geloven AA (2010) Registering the critical view of safety: photo or video?
Surg Endosc 24(10):2527-2530. https://doi.org/10.1007/s0046 4-010-0997-y

73. Booij KA, de Reuver PR, Nijsse B, Busch OR, van Gulik TM, Gouma DJ (2014) Insufficient safety measures reported in operation notes of complicated laparoscopic cholecystectomies. Surgery 155(3):384-389. https://doi.org/10.1016/j.surg.2013.10.010

Publisher's Note Springer Nature remains neutral with regard to jurisdictional claims in published maps and institutional affiliations.

\section{Affiliations}

\section{Lucia llaria Sgaramella ${ }^{1}$ - Angela Gurrado ${ }^{1}$ - Alessandro Pascullii ${ }^{1}$. Nicola de Angelis ${ }^{2}$. Riccardo Memeo ${ }^{3}$. Francesco Paolo Prete ${ }^{1}$. Stefano Berti ${ }^{4}$. Graziano Ceccarelli ${ }^{5}$. Marco Rigamonti ${ }^{6}$. Francesco Giuseppe Aldo Badessi ${ }^{7} \cdot$ Nicola Solari ${ }^{8} \cdot$ Marco Milone $^{9} \cdot$ Fausto Catena $^{10} \cdot$ Stefano Scabini $^{8}$. Francesco Vittore ${ }^{1}$. Gennaro Perrone ${ }^{10}$. Carlo de Werra ${ }^{9} \cdot$ Ferdinando Cafiero $^{8}$ - Mario Testini ${ }^{1} \cdot$ SYoN Italian $^{2}$ Collaborative Group}

\author{
Angela Gurrado \\ angela.gurrado@uniba.it \\ Alessandro Pasculli \\ pascullialessandro@gmail.com \\ Nicola de Angelis \\ nic.deangelis@yahoo.it \\ Riccardo Memeo \\ dott.riccardomemeo@libero.it \\ Francesco Paolo Prete \\ pretef@gmail.com \\ Stefano Berti \\ stefano.berti@asl5.liguria.it \\ Graziano Ceccarelli \\ g.cecca2003@libero.it \\ Marco Rigamonti \\ marco.rigamonti@apss.tn.it \\ Francesco Giuseppe Aldo Badessi \\ francesco.badessi@gmail.com \\ Nicola Solari \\ nicola.solari@hsanmartino.it \\ Marco Milone \\ marco.milone.md@gmail.com \\ Fausto Catena \\ faustocatena@gmail.com \\ Stefano Scabini \\ stefanoscabini@libero.it \\ Francesco Vittore \\ f_vittore@yahoo.it \\ Gennaro Perrone \\ gennaro.perrone@libero.it
}

Carlo de Werra

dewerra@unina.it

Ferdinando Cafiero

ferdinando.cafiero@hsanmartino.it

Mario Testini

mario.testini@uniba.it

1 Unit of General Surgery "V. Bonomo", Department of Biomedical Sciences and Human Oncology, University of Bari “Aldo Moro", Policlinico, Piazza Giulio Cesare, 11, 70124 Bari, Italy

2 Department of Digestive Surgery, Assistance Publique Hôpitaux de Paris, Henri Mondor Hospital, Université Paris-Est (UEP), Créteil, France

3 Department of Emergency and Organ Transplantation, University "Aldo Moro" of Bari, Bari, Italy

4 Department of General Surgery, "Sant'Andrea" Hospital La Spezia, La Spezia, Italy

5 Division of General Surgery, Department of Surgery, San Donato Hospital, via Pietro Nenni 20-22, 52100 Arezzo, Italy

6 Department of General Surgery, Cles Hospital, Cles, Italy

7 Department of General Surgery, "Clinica Sant'Elena" - Quartu Sant'Elena, Quartu Sant'Elena, Italy

8 Department of Surgery, IRCSS Ospedale Policlinico San Martino, Genova, Italy

9 Department of Clinical Medicine and Surgery, Federico II" University, Napoli, Italy

10 Department of Emergency and Trauma Surgery, Parma University Hospital, Parma, Italy 